\title{
Genetic characterization of a mouse line with primary aldosteronism
}

\author{
L G Perez-Rivas1,*, Y Rhayem 1,*, S Sabrautzki2,3, C Hantel1, B Rathkolb²,4,5, \\ M Hrabě de Angelis 2,4,6, M Reincke1, F Beuschlein'1,* and A Spyroglou1,* \\ 'Medizinische Klinik und Poliklinik IV, Endocrine Research Unit, Klinikum der Universität München, \\ LMU, Munich, Germany \\ ${ }^{2}$ Helmholtz Zentrum München, German Research Center for Environmental Health (GmbH), Institute of \\ Experimental Genetics and German Mouse Clinic, Neuherberg, Germany \\ ${ }^{3}$ Helmholtz Zentrum München, German Research Center for Environmental Health (GmbH), Research \\ Unit Comparative Medicine, Neuherberg, Germany \\ ${ }^{4}$ Member of German Center for Diabetes Research (DZD), Neuherberg, Germany \\ ${ }^{5}$ Ludwig-Maximilians-Universität München, Chair for Molecular Animal Breeding and Biotechnology, \\ Gene Center of the Ludwig-Maximilians-Universität München, München, Germany \\ ${ }^{6}$ Lehrstuhl für Experimentelle Genetik, Technische Universität München, Freising-Weihenstephan, \\ Germany \\ *(L G Perez-Rivas, Y Rhayem, F Beuschlein and A Spyroglou contributed equally to this work)
}

Correspondence should be addressed to $\mathrm{F}$ Beuschlein Email

felix.beuschlein@med. uni-muenchen.de

\begin{abstract}
In an attempt to define novel genetic loci involved in the pathophysiology of primary aldosteronism, a mutagenesis screen after treatment with the alkylating agent $\mathrm{N}$-ethyl$\mathrm{N}$-nitrosourea was established for the parameter aldosterone. One of the generated mouse lines with hyperaldosteronism was phenotypically and genetically characterized. This mouse line had high aldosterone levels but normal creatinine and urea values. The steroidogenic enzyme expression levels in the adrenal gland did not differ significantly among phenotypically affected and unaffected mice. Upon exome sequencing, point mutations were identified in seven candidate genes (Sspo, Dguok, Hoxaas2, Clstn3, Atm, Tipin and Mapk6). Subsequently, animals were stratified into wild-type and mutated groups according to their genotype for each of these candidate genes. A correlation of their genotypes with the respective aldosterone, aldosterone-to-renin ratio (ARR), urea and creatinine values as well as steroidogenic enzyme expression levels was performed. Aldosterone values were significantly higher in animals carrying mutations in four different genes (Sspo, Dguok, Hoxaas2 and Clstn3) and associated statistically significant adrenal Cyp11b2 overexpression as well as increased ARR was present only in mice with Sspo mutation. In contrast, mutations of the remaining candidate genes (Atm, Tipin and Mapk6) were associated with lower aldosterone values and lower Hsd3b6 expression levels. In summary, these data demonstrate association between the genes Sspo, Dguok, Hoxaas 2 and Clstn3 and hyperaldosteronism. Final proofs for the causative nature of the mutations have to come from knock-out and knock-in experiments.
\end{abstract}

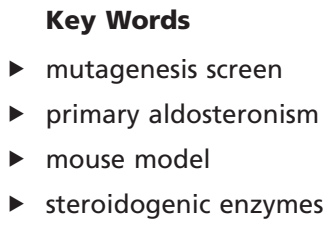

Journal of Molecular Endocrinology (2017) 58, 67-78

\section{Introduction}

Arterial hypertension is a major cardiovascular risk factor affecting $30-45 \%$ of the adult European population (Mancia et al. 2013) with primary aldosteronism being the most frequent cause of endocrine hypertension with a prevalence of $7-10 \%$ in unselected hypertensive patients (Rossi et al. 2006, Hannemann et al. 2012). The large

Published by Bioscientifica Ltd 
majority of primary aldosteronism (PA) is caused either by an aldosterone-producing adrenal adenoma or by bilateral adrenal hyperplasia (Mulatero et al. 2004, Rossi et al. 2006). Despite its high prevalence, so far, the genetic causes of primary aldosteronism due to bilateral hyperplasia have been elucidated only in a very small subgroup of cases: Familial hyperaldosteronism type I is caused by unequal crossing-over of the CYP11B1 and CYP11B2 and the formation of a hybrid gene (Sutherland et al. 1966, Lifton et al. 1992), responsible for ACTH-dependent production of aldosterone instead of being regulated by angiotensin II. Familial hyperaldosteronism type II (FH-2) also seems to be inherited as an autosomal dominant trait. A locus has been mapped on chromosome 7p22 in some but not all families (Gordon et al. 1991, So et al. 2005), but the linkage area has not been resolved to any causative mutation. Familial hyperaldosteronism type III (FH-3) (Geller et al. 2008), however, has been recently linked to gain-of-function mutation in the KCNJ5 gene, encoding an inwardly rectifying potassium channel (Choi et al. 2011). These mutations induce a loss in channel selectivity, depolarization and increased intracellular $\mathrm{Ca}^{2+}$ concentrations leading to aldosterone excess. In a recent genetic analysis in 46 patients from 21 European families, a new germline G151E mutation was identified (Mulatero et al. 2012). KCNJ5 mutations are more prevalent in women and younger patients, and correlate with higher plasma aldosterone levels (Boulkroun et al. 2012). Furthermore, exome sequencing in aldosterone producing adrenal adenomas revealed somatic mutations in ATP1A1 and ATP2A3, two members of the P-type ATPase gene family (Beuschlein et al. 2013, Fernandes-Rosa et al. 2014). Finally, germline mutations in the $\mathrm{Ca}^{2+}$-channel genes CACNA1D (Scholl et al. 2013) and CACNA1H (Scholl et al. 2015) have been found as a rare cause of PA of early onset with CACNA1D mutations additionally causing neuromuscular abnormalities and partial or generalized seizures (Scholl et al. 2013). CACNA1H mutations were documented in patients with different phenotypic presentations of primary aldosteronism, such as earlyonset primary aldosteronism, familial hyperaldosteronism or aldosterone-producing adrenal adenoma (Daniil et al. 2016). All in all, genetics of the vast majority of cases of bilateral adrenal hyperplasia remain enigmatic.

Animal models can play an important role in gaining functional insights into the physiology of aldosterone regulation and on the pathophysiology of autonomous aldosterone secretion. Furthermore, they can be used for the investigation of cardiovascular effects of autonomous aldosterone synthesis on several organs and can serve for pharmacologic intervention studies. So far, though, only a few mouse models have been described with a phenotype reminiscent of primary aldosteronism. A mouse with TASK channel deletion (Davies et al. 2008, Heitzmann et al. 2008) and a circadian clock-deficient cry-null mouse model showing an upregulation of the adrenal Hsd3b6 (Doi et al. 2010) belong to this group. An approach to develop new mouse models for a specific phenotype is induction of genetic variation by random mutagenesis of the mouse genome using the mutagenic substance $\mathrm{N}$-ethyl- $\mathrm{N}$-nitrosourea (ENU) (Hrabe de Angelis et al. 2000, Hagge-Greenberg et al. 2001, Clark et al. 2004). ENU is an alkylating agent that causes ethylation of nucleic acids and thereby point mutations in pre-meiotic spermatogonial stem cells (Russell et al. 1979, Rinchik 1991). The mutations derived from ENU handling may, therefore, be hypomorphic (partial loss of function). Mutants with gain-of-function as well as complete loss-offunction mutations are also possible (Justice et al. 2000, Noveroske et al. 2000). In the case of phenotype-driven genetics, the genomic association is accomplished utilizing common single-nucleotide polymorphisms (SNPs) or more recently exome sequencing.

Objective of the present study was to phenotypically characterize a mouse line generated using this mutagenesis screen and to identify candidate genes correlating with the phenotype of primary aldosteronism.

\section{Materials and methods}

\section{Animals and housing conditions}

All animal studies were performed according to protocols examined and approved by the Regierung von Oberbayern and according to the German Animal Protection Law. Mice were kept in a specific pathogen-free animal facility area at an ambient temperature of $22 \pm 2^{\circ} \mathrm{C}$, (relative humidity $60 \pm 5 \%$ ) and on a $12 \mathrm{~h}-12 \mathrm{~h}$ light-darkness cycle. Animals were fed with chow \#1314 (Altromin/Lage, Germany) ad libitum and had free access to tap water. $\mathrm{C} 3 \mathrm{HeB} / \mathrm{FeJ}$ mice (Jackson Laboratory) involved in the experiments were maintained in groups of three or less individuals per cage. The generation of this mouse line with hyperaldosteronism has been described previously (Spyroglou et al. 2011). In brief, in the Munich ENU project performed at the Institute of Experimental Genetics of the Helmholtz Center Munich, $\mathrm{C} 3 \mathrm{HeB} / \mathrm{FeJ}$ male mice were treated with three weekly injections of $90 \mathrm{mg} / \mathrm{kg}$ ENU at approximately $10-14$ weeks of age. Recovery of fertility upon treatment could be observed approx. 80 days later. All F1 offspring from ENU-treated males and wild-type females born at

Published by Bioscientifica Ltd 
least after two cycles of spermatogenesis following the last injection were checked for their aldosterone levels in plasma at the age of 12 and 16 weeks. Out of this cohort of 2800 offspring, 83 displayed high aldosterone values at the age of 12 weeks, and upon confirmation measurement at the age of 16 weeks, only 11 mice had sustained high aldosterone values ( 2 males and 9 females). Upon mating to wild-type mice, eight lines with affected offspring in the heterozygous state had been established. Here, we describe the phenotypical and genetic characterization of one of these mouse lines.

\section{Blood sampling}

To avoid any influence of the examined parameters through hypothalamic-pituitary-adrenal (HPA) axis activation, handling of the animals until blood sampling was kept to an interval of less than one minute. Blood sampling took place between 08:00 and 11:00 h for all animals. After effective inhalation anesthesia, the retrobulbar vein plexus of the mouse was punctured with a glass capillary (external diameter $0.8 \mathrm{~mm}$ ), and from each animal, blood was collected in Li-Heparin-coated tubes to avoid coagulation. After centrifugation $(10,000 \mathrm{~g}, 10 \mathrm{~min})$, plasma was separated and kept at $-20^{\circ} \mathrm{C}$ until measurement.

\section{Biochemical and endocrine profiling}

Urea and creatinine values were measured in the clinical chemical laboratory of the German Mouse Clinic (Fuchs et al. 2011) using an AU480 Autoanalyser (BeckmanCoulter/Krefeld, Germany) and adapted reagent kits provided by the manufacturer (urea: OSR6134; creatinine (Jaffe): OSR6178) (Rathkolb et al. 2013).

Aldosterone was determined in $50 \mu \mathrm{L}$ of mouse plasma samples with an in-house time resolved fluorescent immunoassay as described in detail elsewhere (Manolopoulou et al. 2008).

After $1.5 \mathrm{~h}$ of incubation of two equal fractions of each mouse plasma sample with plasma of bilaterally nephrectomized male rats as renin substrate at $0^{\circ} \mathrm{C}$ and $37^{\circ} \mathrm{C}$, respectively $(\mathrm{pH}=6$, with addition of the protease inhibitor PMSF), angiotensin I was generated. Subsequently, angiotensin I concentration of each fraction was measured by a commercially available angiotensin I (PRA) ELISA Kit (IBL International, Hamburg, Germany) according to the manufacturer's instructions. Plasma renin activity in each sample was calculated using the following equation: $\quad$ PRA $=\left[\left(\right.\right.$ AngI $37^{\circ} \mathrm{C}-$ AngI $\left.0^{\circ} \mathrm{C}\right) /$ incubation time $(\mathrm{h})]^{*} 1.11$. Aldosterone-to-renin ratios (ARR) were calculated for each mouse sample and expressed as \% of the mean of male or female wild types, respectively.

Corticosterone levels were measured with the Corticosterone HS EIA Immunoassay (IDS, Boldon, Tyne and Wear, United Kingdom) according to the manufacturers' instructions.

\section{Organ sampling}

After anesthesia, mice were killed, and the abdominal cavity was opened. Both adrenal glands of each mouse, as well as the spleen were identified and removed. Directly after collection, adrenals were cleaned from surrounding fat tissue using a stereoscope. All organs were snapfrozen in liquid nitrogen and stored at $-80^{\circ} \mathrm{C}$ or stored in $4 \%$ paraformaldehyde and subsequently embedded in paraffin blocks.

\section{Capture and sequencing of murine exomes}

In-solution targeted enrichment of exonic sequences was performed by DNA extracted from the spleens of two different affected animals from the first and third generation, respectively, using the SureSelectXT Mouse All Exon $50 \mathrm{Mb}$ kit from Agilent as already described (Diener et al. 2016). The generated libraries were indexed, pooled and sequenced as $100 \mathrm{bp}$ paired-end runs on a HiSeq2000 system (Illumina, San Diego, CA, USA).

\section{Mapping and variant calling}

Read alignment to the mouse genome assembly $9 \mathrm{~mm}$ was done with Burrows-Wheeler Aligner (BWA, version 0.6.2) and yielded 12.1 and $11.5 \mathrm{~Gb}$ of mapped sequence data corresponding to an average coverage of $143 \times$ and $137 x$, respectively. Single-nucleotide variants (SNVs) and small insertions and deletions (indels) were detected with SAMtools (version 0.1.18). SNVs were only lightly filtered on quality scores (SNV quality $>40$, mapping quality $>50$ ) because we preferred false positives to negatives. After subtracting variants from dbSNP128 and from 158 other mice in our in-house database, 31 unique coding variants specific to the mutant mouse line remained.

\section{Validation of candidate variants by capillary Sanger sequencing}

Candidate SNVs were further investigated by amplifying DNA of mutant and control mice with intronic primers (Supplementary Table 1, see section

Published by Bioscientifica Ltd 
on supplementary data given at the end of this article). Bidirectional Sanger sequencing was then performed using the ABI Prism BigDye Terminator, v.3.1 Cycle Sequencing Kit on an ABI Prism 3700 DNA Analyzer (Applied Biosystems, Thermo Fisher Scientific). A genotype-phenotype correlation was then performed.

\section{Real-time PCR}

Both adrenals from each individual animal were combined and homogenized in extraction buffer while still frozen. RNA extraction was performed using the Maxwell 16 LEV simplyRNA according to the manufacturer's instructions (Promega). RNA quantification was performed with the NanoDrop spectrophotometer. The 260/280-absorbance ratio was used to assess RNA purity. Additionally, RNA integrity was assessed on denaturing agarose gel stained with ethidium bromide. For cDNA synthesis, 500 ng of total RNA were reverse transcribed according to the manufacturers' instructions (M-MLV Reverse Transcriptase, dNTP Mix, Recombinant RNasin Ribonuclease Inhibitor all from Promega). The expression of selected genes involved in steroidogenesis was investigated: StAR (steroidogenic acute regulatory protein), Cyp11a1 (cholesterol side-

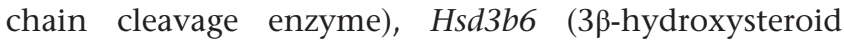
dehydrogenase), Cyp11b1 (11ß-hydroxylase), Cyp11b2 (aldosterone synthase), Nurr1, Nur77 and Kim1 (kidney injury molecule-1, Havcr1). Gapdh was used as reference gene. For primer sequences, see Supplementary Table 1 . The SsoFast EVAGreen Supermix (Biorad Laboratories) in the Mx3000P QPCR System (Stratagene) was used for the quantification of the investigated genes. Realtime PCR conditions in the Mx3000P are as indicated in Supplementary Table 1 . To verify the presence of a unique amplicon with the correct size, a melting curve analysis was performed between $55^{\circ}$ and $95^{\circ} \mathrm{C}\left(0.1^{\circ} \mathrm{C} / \mathrm{s}\right)$ and the products were run on a $1 \%$ agarose gel. To proof the specificity of the amplification product for each primer pair, we performed sequencing of the different genes with the primers used for the qPCR experiments. Quantification was adjusted using the mouse Gapdh expression as reference. With a coefficient of variation $(\mathrm{CV})$ below $5 \%$, Gapdh was considered to have a stable expression in the adrenal gland and therefore was chosen to be used as housekeeping gene in this experimental setting.

\section{Histological examination}

Tissues remained in 4\% paraformaldehyde overnight and then were dehydrated, embedded in paraffin, sectioned and stained with hematoxylin and eosin following standard protocols. Hematoxylin and eosin-stained adrenal sections were examined with a light microscope using magnifications of $\times 40$ and $\times 400$.

For CYP11B2 immunohistochemistry, paraffinembedded sections were rehydrated, blocked with $0.3 \% \mathrm{H}_{2} \mathrm{O}_{2}$ in methanol for $10 \mathrm{~min}$ and incubated with blocking buffer $(0.1 \mathrm{M}$ Tris- $\mathrm{HCl} \mathrm{pH}=7.4$ (SigmaAldrich), 20\% goat serum (Jackson ImmunoResearch Laboratories) and $0.05 \%$ SDS (Sigma-Aldrich)) for $1 \mathrm{~h}$. CYP11B2 was immunodetected overnight at $4^{\circ} \mathrm{C}$ by means of a rabbit-anti-mouse-CYP11B2 antibody (kindly provided by Prof Celso Gomez-Sanchez, University of Mississippi, USA) in a dilution of 1:1000 in an antibody buffer containing $0.1 \mathrm{M}$ Tris- $\mathrm{HCl}, 20 \%$ goat serum and $0.1 \%$ Tween 20 (Sigma-Aldrich). After rinsing for 15 min in PBS, secondary antibody (goat-anti-rabbitbiotinylated IgG (Vector Laboratories, Burlingame, CA, USA)) in a dilution of 1:2000 in antibody buffer was applied for $30 \mathrm{~min}$ at room temperature. For the visualization of the bound CYP11B2 antibody, Vectastain Elite ABC system (Vector Laboratories) and Sigma Fast diaminobenzidine (Sigma-Aldrich) were used, and slides were counterstained with Harry's hematoxylin.

All captured images were color-calibrated to the negative control. A randomly selected rectangle area of the adrenal cortex of each animal extending vertically from the outer border of the adrenal medulla up to the surface of the adrenal gland was divided into three subareas (outer $(1 / 4)$, middle $(2 / 4)$ and inner area (1/4)). The total counterstained cell population of the selected area was analyzed according to the color of the cell cytoplasm; cells were categorized as positive or negative. Positively and negatively CYP11B2 - stained cells were counted on three independent sections per animal by two independent investigators under blinded conditions. Results are presented as means of ratios of positive to total cell counts per standardized area.

\section{Statistical analysis}

Statistical analysis was carried out with the Prism 3.02 (GraphPad Software). Statistical significance was determined using the unpaired $t$-test for normally distributed parameters and Mann-Whitney test for nonnormally distributed parameters. Statistical significance was denoted by asterisks in the figures as ${ }^{*} P<0.05$, ${ }^{* *} P<0.01$ and ${ }^{* * *} P<0.001$.

Published by Bioscientifica Ltd 


\section{Results}

\section{Screening parameters}

All offspring of the founder animal ( $n=158$, Fig. 1) were tested for their aldosterone values at the age of 12 and 16 weeks. Animals repeatedly showing increased values were grouped to the 'affected group' and those with normal values (normal rage: mean \pm 3 S.D., defined previously (Spyroglou et al. 2011)) to the 'unaffected group'. Out of this cohort, 33 animals (17 unaffected and 16 affected) from generations F3-5 were further analyzed. As expected, affected animals of both genders had significantly higher aldosterone values than their unaffected littermates $(P<0.001$, Fig. 2A, 33\% of all offspring of this mouse line were affected and the affected male:female ratio was 4:3). Corticosterone levels of affected and unaffected animals of both genders did not differ significantly (unaffected: $2.64 \pm 1.5 \mathrm{ng} / \mathrm{mL}$, affected $2.36 \pm 1.79 \mathrm{ng} / \mathrm{mL}, \quad P=0.75)$, and no correlation of aldosterone to corticosterone values could be observed $(R=0.16, P=0.52)$, excluding increased stress as confounding factor for the elevated aldosterone values. Urea and creatinine, as parameters of kidney function, showed no differences between affected animals and their unaffected littermates, suggesting that secondary hyperaldosteronism due to overt renal disease can be excluded in this mouse line (Fig. 2B and C). Consistently, the expression of Kim1, as a biomarker of renal tubule injury, did not differ in the two groups (relative expression normalized to Gapdh: unaffected: $0.08884 \pm 0.01548$, affected: $0.1163 \pm 0.03992, P=0.46$ ).

Expression levels of several genes involved in steroidogenesis were quantified in the adrenal glands of these animals. Unexpectedly, the expression levels of all investigated steroidogenic enzymes (StAR, Cyp11a1, Hsd3b6, Cyp11b1 and Cyp11b2) and orphan nuclear factors (Nurr1 and Nur77-data not shown) did not display any statistically significant differences between unaffected and affected animals (Fig. 2D, E, F, G, H and I).

\section{Identified candidate genes}

For the genotypic characterization of the mouse line, we made use of next-generation sequencing (NGS) exome analysis (Institute of Human Genetics, Helmholtz Center, Munich, Germany (Diener et al. 2016)). After exome sequencing performed on two different affected animals from the first and third generation, respectively, a list with induced single-nucleotide variations (SNV), filtered on the basis of technical quality criteria (SNV quality $>40$, mapping quality $>50$ ), was generated (Supplementary Table 2). Exome sequencing identified SNVs on 31 different genes; eight of those were common for both investigated animals: SCO-spondin (Sspo), deoxyguanosine kinase (Dguok), 5730446D14Rik (Hoxa cluster antisense RNA 2 - Hoxaas2), calsyntenin 3 (Clstn3), integrator complex subunit 10 (Ints10), ataxia telangiectasia mutated (Atm), timeless interacting protein (Tipin) and mitogenactivated protein kinase 6 (Mapk6). Sspo, Dguok, Hoxaas2 and Clstn3 are located on mouse chromosome 6, Ints10 is located on chromosome 8 and Atm, Tipin and Mapk6 are located on chromosome 9 . These were subsequently sequenced in a large cohort ( $n=126,63$ females, 63 males) of phenotypically 'affected' and 'unaffected' animals of this mouse line. Ints10 was not found mutated in the examined cohort of animals and was excluded from further analyses. As ENU is likely to induce more coding SNVs in the first generations than the one responsible for the 'high aldosterone' phenotype, we again investigated the potential function of those genes and their expression levels in the adrenal gland. Based on a detailed database search, none of the genes had a known function in the adrenal gland and/or aldosterone biosynthesis. Increased adrenal expression according to the BioGPS database could be documented only for the murine Clstn3 gene.

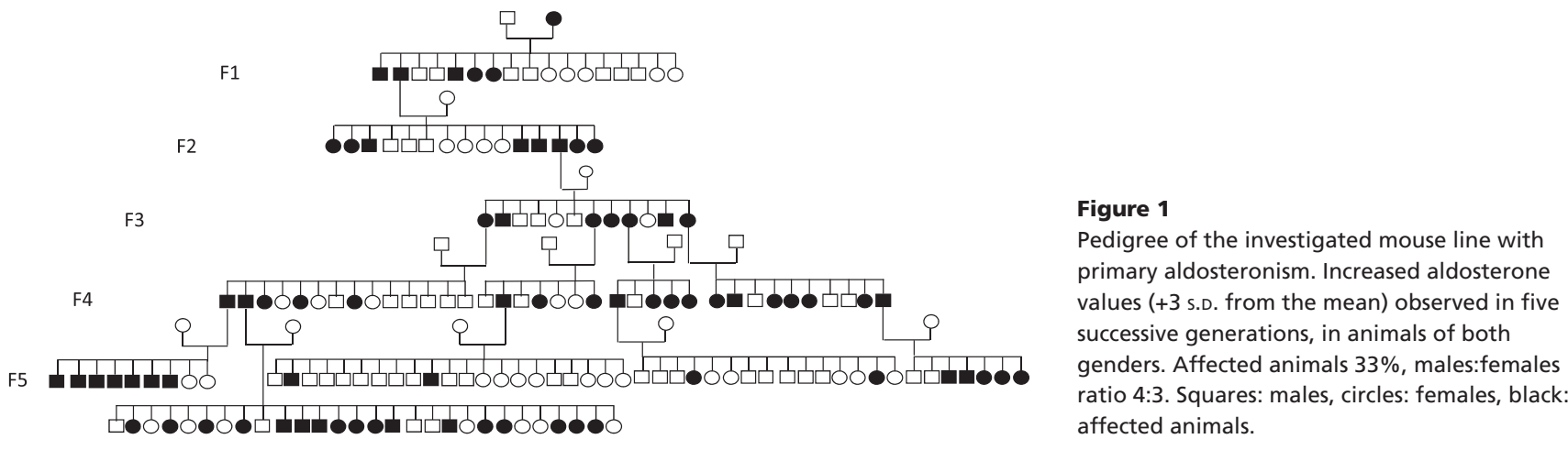


A

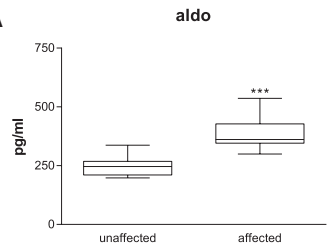

D

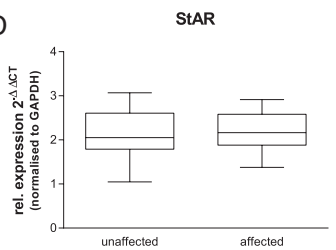

G

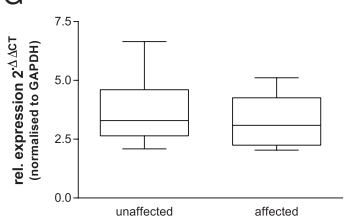

B

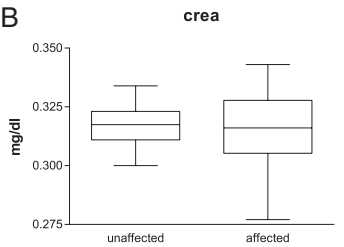

E Cyp11a1
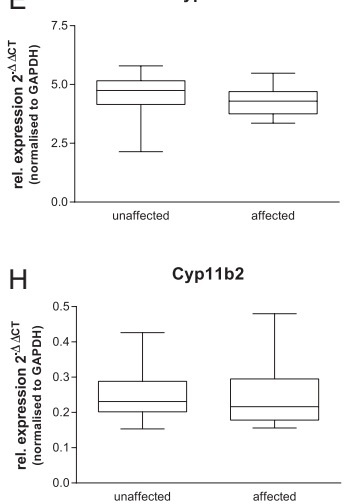

C
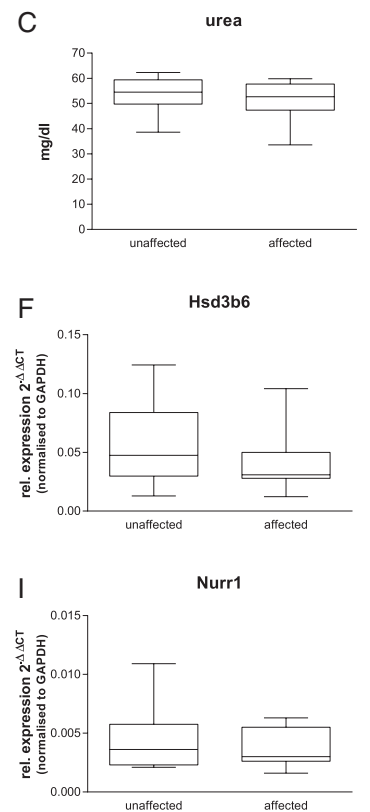

Figure 2

(A) Aldosterone values in affected mice $(n=16)$, significantly higher than that in their unaffected littermates $(n=17, P<0.001)$. No differences in creatinine and urea values in affected and unaffected animals (B, C). No differences in the expression levels of the steroidogenic enzymes leading to aldosterone production ( $D, E, F, G, H$, and I).

\section{Genotype/phenotype correlation}

In an attempt to correlate the identified candidate genes with the phenotype of interest, animals were stratified into wild-type and mutated groups according to their genotypes for each of the candidate genes. We correlated the genotype with the respective aldosterone, urea and creatinine values as well as steroidogenic enzyme expression levels. To uniformly assess the differences in the aldosterone values in mice of both genders, these were expressed as percentage of the mean of the respective gender. Due to the fact that the majority of investigated animals carried more than one of the seven SNVs identified during the study, for the results depicted in Figs 3 and 4, animals carrying two wild-type copies for the respective gene were considered as 'wild types'. Thus, in the majority of cases, these animals were carriers of mutant variants of one or several genes of the panel. Along the same line, 'mutants' for the specific gene also often carried in parallel further mutations. Thereby we aimed at isolating a potential effect of one mutation on the investigated phenotype even though the random presence of other variants might have further modulating effects. We observed significantly increased plasma aldosterone values in animals carrying an Sspo $(P<0.01)$, Dguok $(P<0.01)$, Hoxaas2 $(P<0.01)$ and Clstn3 $(P<0.001)$ mutation. In contrast, animals carrying the wild-type gene for Atm, Tipin and Mapk6 displayed significantly higher aldosterone values than their mutant littermates (Fig. 3). Urea and creatinine levels did not differ significantly among wild-type and mutated animals.

The correlation of the expression levels of steroidogenic enzymes to the genotypes was less clear-

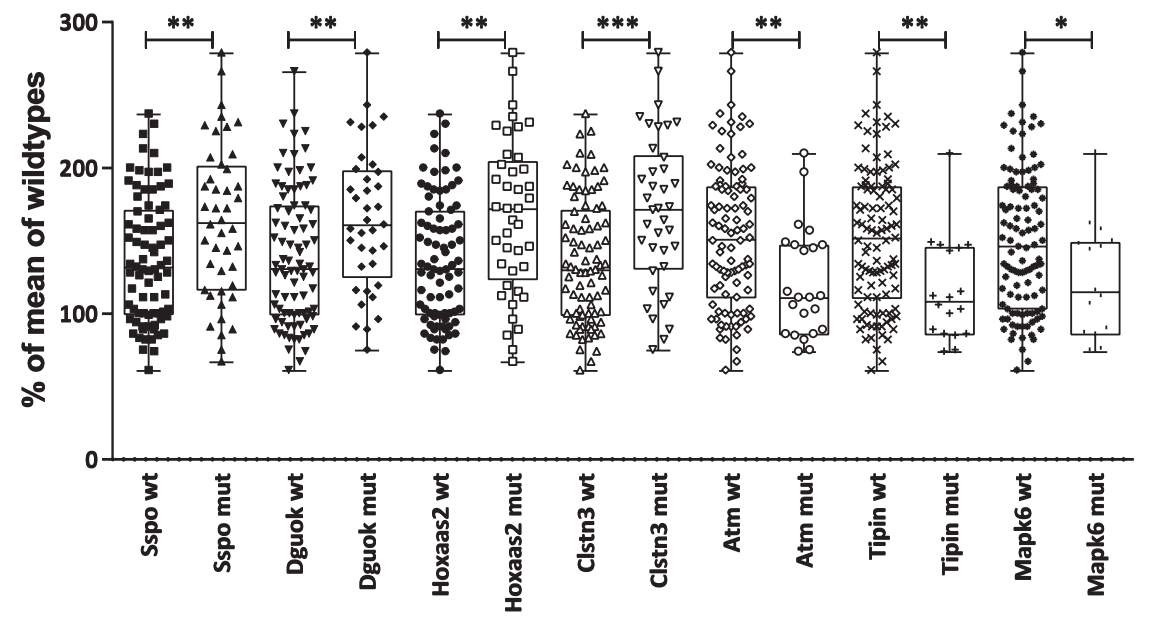

Figure 3

Aldosterone values in wild-type or mutant animals $(n=126)$ for each of the following genes: Sspo, Dguok, Hoxaas2, Clstn3, Atm, Tipin and Mapk6. Values are expressed as \% of the mean aldosterone levels of wild-type male or female mice, respectively. http://jme.endocrinology-journals.org DOI: 10.1530/JME-16-0200
๑) 2017 Society for Endocrinology Printed in Great Britain 

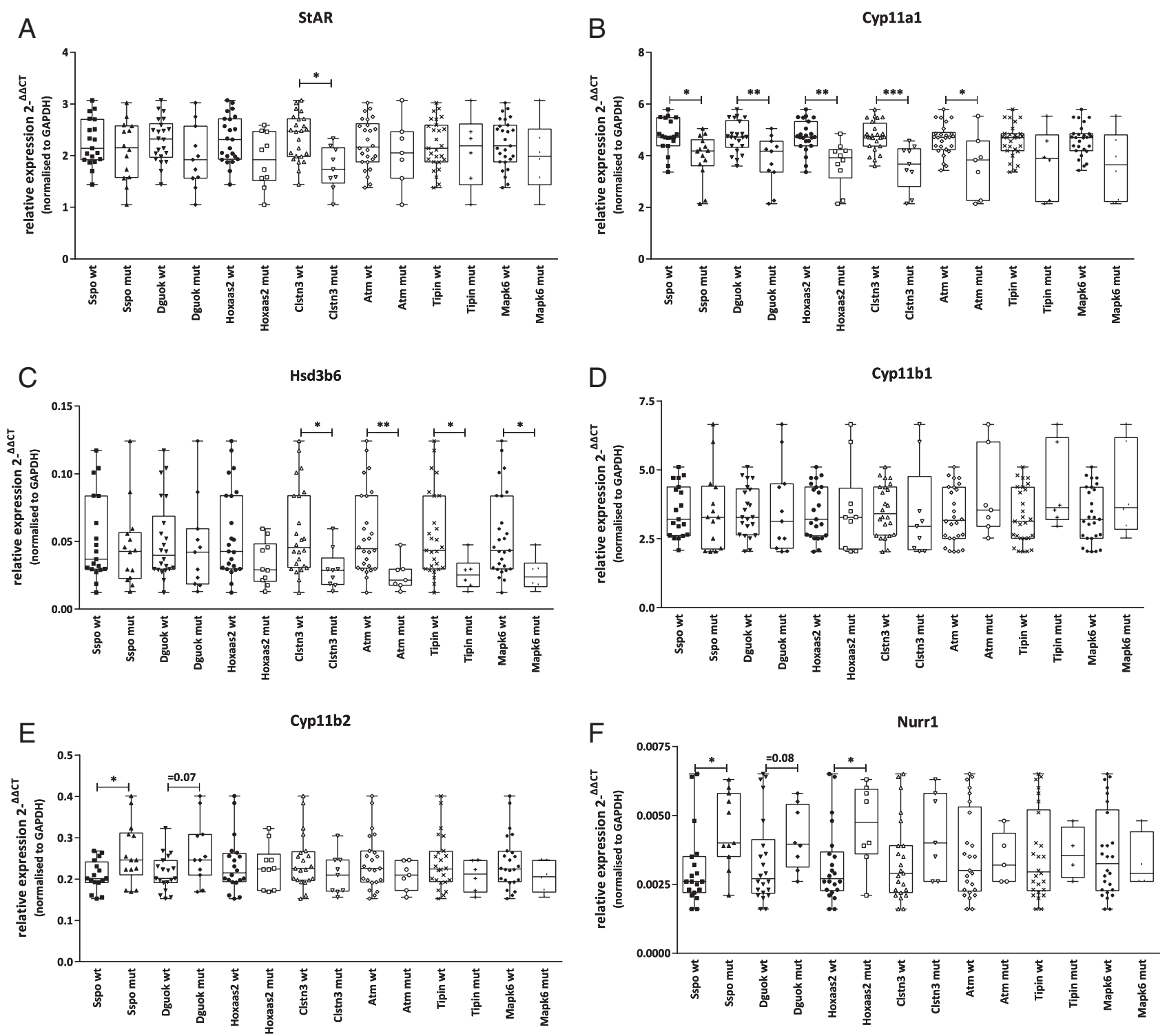

Figure 4

Expression levels of steroidogenic enzymes involved in aldosterone biosynthesis in wild-type or mutant animals $(n=33)$ for each of the following genes: Sspo, Dguok, Hoxaas2, Clstn3, Atm, Tipin and Mapk6. Values are relatively expressed to the housekeeping gene Gapdh.

cut with large variation among wild-type and mutated animals in most of the cases. StAR expression levels, regulating the initial step in steroidogenesis, were significantly lower in Clstn3-mutated animals $(P<0.05$, Fig. 4A), whereas Cyp11a1 expression was lowered in Sspo $(P<0.05)$, Dguok $(P<0.01)$, Hoxaas $2(P<0.01)$, Clstn3 $(P<0.001)$ and Atm $(P<0.05)$ mutants (Fig. 4B). Significantly lower were also the Hsd3b6 levels in Clstn3 $(P<0.05)$, Atm $(P<0.01)$, Tipin $(P<0.05)$ and Mapk6 $(P<0.05)$ mutated animals (Fig. 4C). No such differences could be found for Cyp11b1 expression levels for any of the mutations investigated (Fig. 4D). In
Sspo-mutated animals, Cyp11b2 expression, as marker of the rate-limiting step of aldosterone biosynthesis, was significantly higher $(P<0.05)$. Dguok-mutated animals showed a tendency to higher Cyp11b2 levels, without reaching statistical significance $(P=0.07)$, (Fig. 4E). The orphan nuclear factor Nurr1, also involved in the aldosterone synthesis was found significantly higher in Sspo- $(P<0.05)$ and Hoxaas $2-(P<0.05)$ mutated mice. Dguok mutants also tended to display higher Nurr1 levels $(P=0.08)$, (Fig. 4F).

From the results depicted in Fig. 3, we conclude that Atm, Tipin and Mapk6 do not correlate with the phenotype 


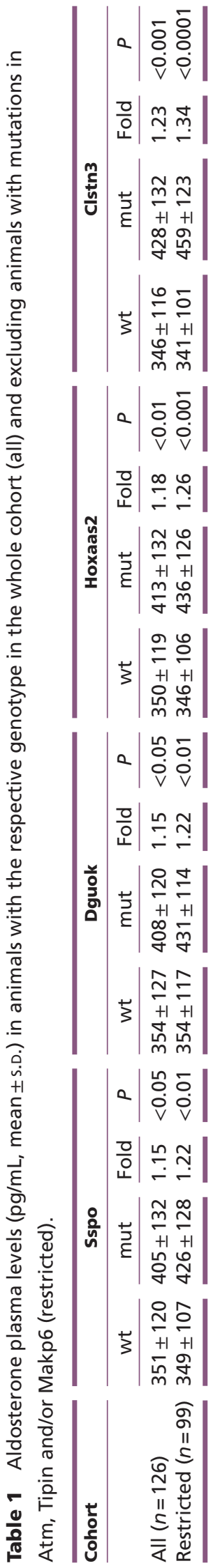

http://jme.endocrinology-journals.org DOI: 10.1530/JME-16-0200
(C) 2017 Society for Endocrinology Printed in Great Britain of primary aldosteronism as aldosterone values in wildtype animals were found to be significantly higher than those in animals carrying one, two or all three SNVs. To further narrow down our list to one causative SNV from the remaining four genes (Sspo, Dguok, Hoxaas2 and Clstn3), we compared the aldosterone levels of animals excluding mice carrying Atm and/or Tipin and/or Mapk6 mutations. Animals carrying Sspo and/or Dguok and/or Hoxaas2 and/or Clstn3 SNVs displayed significantly higher aldosterone values than wild-type only animals and the mutant-to-wild-type ratio was in all cases higher in this restricted analysis (Table 1, for detailed combination of the variants see Supplementary Table 3). A combination of SNVs in both chromosomes 6 and 9 (all seven mutations) leads to weakening of the phenotype of hyperaldosteronism (data not shown).

Quantification of plasma renin activity in these animals did not present any significant differences between animals with wild-type and mutant genotype for the above four SNVs. Calculation of the aldosterone-torenin ratios (ARR) showed a significant ARR increase only in mice carrying the Sspo SNV (Table 2). Mice with the Dguok and/or Hoxaas2 SNV presented a tendency toward increased ARRs.

Interestingly, when comparing corticosterone levels of animals carrying the four different mutations to their wild-type littermates, it could be observed that mutant animals displayed slightly lower corticosterone values than the wild types without reaching statistical significance (mutants: $2.36 \pm 0.53 \mathrm{ng} / \mathrm{mL}$ vs wild types: $4.06 \pm 0.95 \mathrm{ng} / \mathrm{mL}, P=0.14)$.

Histological examination of the adrenal glands of animals carrying all four SNVs (Sspo, Dguok, Hoxaas2 and Clstn3) did not reveal any adrenocortical adenomas. Moreover, there was no indication of hyperplasia as the cell count of the outer, middle and inner cortical area of these animals did not differ significantly from the wild types ( $P=0.45, P=0.80$ and $P=0.29$, respectively). However, immunohistochemical staining with murine CYP11B2 antibody showed significantly more positively stained cells in the adrenal cortex of mutant animals in comparison to the wild types $(P<0.001$, Fig. 5A, B and C). Additionally, in the adrenal cortex of mutant animals, CYP11B2 staining was significantly more pronounced in the middle $(P<0.001)$ and inner $(P<0.001)$ area when compared to wild types, suggesting an alternated zonation pattern in animals carrying the four SNVs (Fig. 5D, E and F). Thereby the presence of aldosterone synthase expression in the middle and

Published by Bioscientifica Ltd 
Table 2 Aldosterone-to-renin ratio of all experimental animals. In each line 'mut' denotes those mice which carry at least the respective mutant gene, whereas ' $w t^{\prime}$ ' combine those with the absence of the mutant gene.

\begin{tabular}{|c|c|c|c|}
\hline Aldosterone-to-renin ratio (ARR) & & $\begin{array}{l}\text { Mean } \pm \text { S.D. }(\% \text { of } \\
\text { mean of wild types) }\end{array}$ & P-value \\
\hline Sspo & $\begin{array}{l}\text { wt }(n=24) \\
\text { mut }(n=17)\end{array}$ & $\begin{array}{l}100 \pm 43 \\
142+71\end{array}$ & $<0.05$ \\
\hline Dguok & $\begin{array}{l}\text { wt }(n=27) \\
\text { mut }(n=14)\end{array}$ & $\begin{array}{l}100 \pm 49 \\
130 \pm 60\end{array}$ & 0.09 \\
\hline Hoxaas2 & $\begin{array}{l}\text { wt }(n=27) \\
\text { mut }(n=14)\end{array}$ & $\begin{array}{l}100 \pm 47 \\
130 \pm 65\end{array}$ & 0.10 \\
\hline Clstn3 & $\begin{array}{l}\text { wt }(n=26) \\
\text { mut }(n=15)\end{array}$ & $\begin{array}{l}100 \pm 46 \\
96 \pm 55\end{array}$ & 0.80 \\
\hline
\end{tabular}

inner cortical area of the mutant animals seems to exclusively account for the increased total expression of aldosterone synthase.

\section{Discussion}

In this study, an ENU mutagenesis-derived mouseline with hyperaldosteronism was phenotypically and genetically characterized. The trait of increased aldosterone values above 3 s.D. from the mean was preserved for more than five generations in a considerable proportion of animals of both genders. Specifically, one-third of all investigated animals were affected, with the ratio of males to females being 4:3. Animals with high aldosterone values showed in all cases normal kidney retention parameters and
Kim1 expression excluding a relevant renal disorder as the cause for the described phenotype. Furthermore, corticosterone levels, mirroring stress levels of affected and unaffected animals, did not differ in the present study. However, the adrenal expression of steroidogenic enzymes and especially $C y p 11 b 2$, the rate-limiting step of aldosterone biosynthesis was not concordant with the significantly increased plasma aldosterone levels. Although blood pressure measurement would have been a clinically relevant endpoint in the investigation of this mouse model in the context of the current study, we focused on the adrenal phenotype of these animals. Future investigations with state-of-the-art analytic methods will be required to investigate in depth the cardiovascular effects of the animal model.
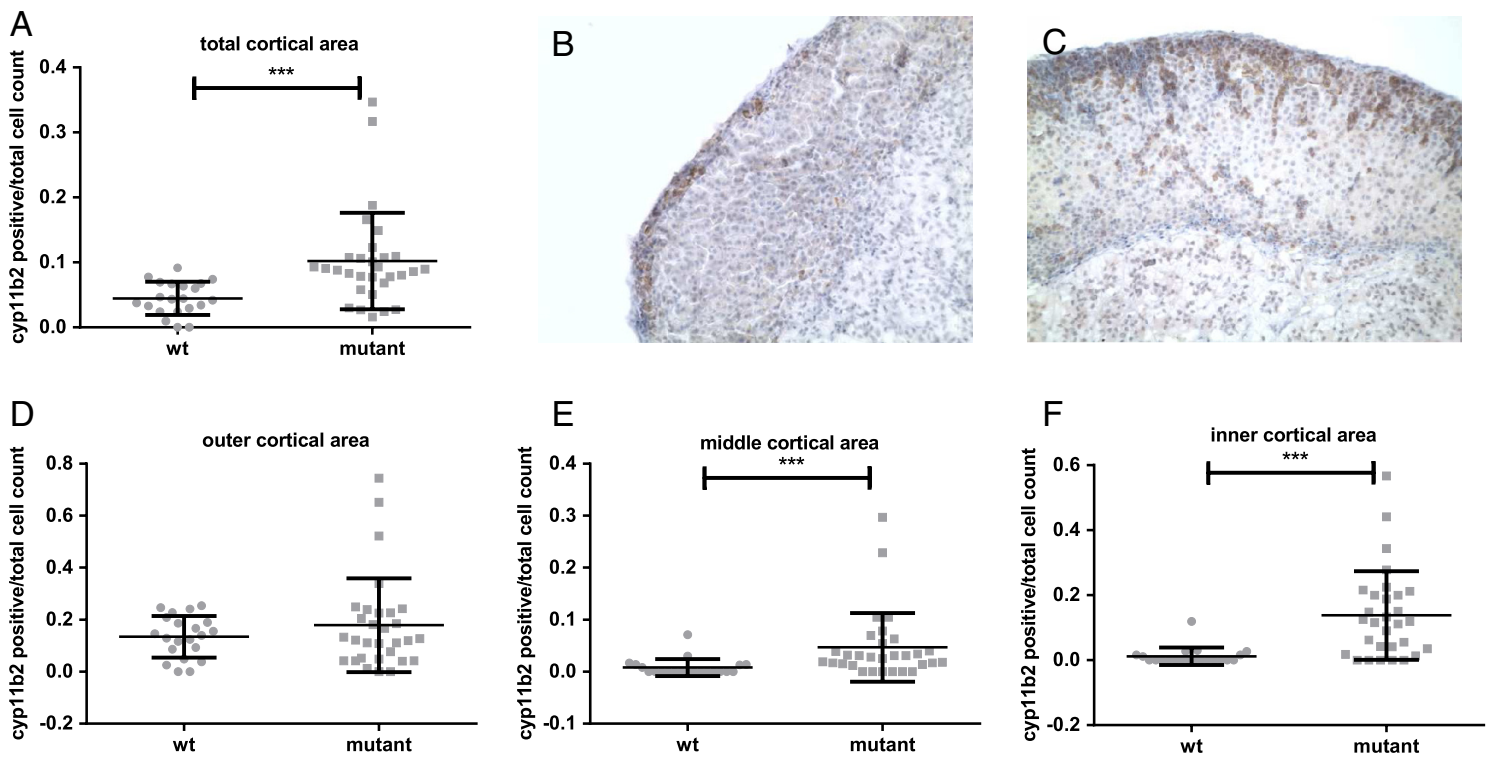

Figure 5

Histological examination of the adrenal glands of wild-type animals and mutants for all four following genes: Sspo, Dguok, Hoxaas2 and Clstn3. Cell count of CYP11B2 positively stained cells per standardized area in the adrenal cortex of wild-type and mutant animals to the total cell count per area (A). Representative immunohistochemical staining of the adrenal cortex of wild-type (B) and mutant (C) mice. Ratios of CYP11B2 positively stained cells to the total cell count in the outer (D), middle (E) and inner (F) area of the adrenal cortex of wild-type and mutant mice $(* * *$ for $P<0.001)$.

http://jme.endocrinology-journals.org DOI: 10.1530/JME-16-0200
(C) 2017 Society for Endocrinology Printed in Great Britain
Published by Bioscientifica Ltd 
Following the described approach, we identified seven candidate genes for the phenotype hyperaldosteronism. Out of the identified genes, none had a known function in aldosterone secretion or regulation and only Clstn 3 had a pronounced expression in the mouse adrenal gland as well as in the pituitary and brown adipose tissue according to the BioGPS database. Clstn 3 codes for a postsynaptic $\mathrm{Ca}^{2+}$-binding membrane protein, a member of the cadherin superfamily involved in the development of synapses (Lu et al. 2014), with the highest expression levels in GABAergic neurons (Hintsch et al. 2002). It is also present in endocrine secretory granules of gonadotrope, somatotrope and thyrotrope cells of the anterior pituitary, whereas CLSTN1, another member of the superfamily, was found to be localized in glucagon-containing secretory granules of pancreatic $\alpha$-cells (Rindler et al. 2008). Thus, it is hypothesized that soluble Clstns, released locally, could potentially serve as modulators of endocrine function (Rindler et al. 2008). Although Clstn3 has not been appreciated to play a functional role in adrenal physiology or disease, it is the strength of a hypothesisfree approach such as the ENU screen that potentially surprising findings can be generated. Exome sequencing from patient samples (Beuschlein et al. 2013, 2014) and population-based genetic studies (Spyroglou et al. 2014) provide examples for the power of these strategies.

When aldosterone values were displayed with mice grouped according to the presence or absence of specific mutations, an interesting phenomenon was observed: Animals carrying part of the identified mutations displayed significantly lower aldosterone levels compared to the wild types for the specific mutation. An explanation for this paradoxical finding could be that animals were misleadingly grouped into 'mutant' and 'wild types' for the specific genes as these genotypes were not responsible for the phenotype of interest. Accordingly, Atm, Tipin and Mapk6, all located on chromosome 9 and apparently inherited in parallel, probably due to genetic linkage, seem not to be causative for the hyperaldosteronism phenotype as aldosterone values of 'wild-type' animals were in these three cases higher than those in their 'mutant' littermates. In contrast, it was reassuring that SNVs on Sspo, Dguok, Hoxaas2 and Clstn3, all located on chromosome 6, were associated with a significant increase in aldosterone values of the respective mutant animals, suggesting a role of these genes in the phenotype of primary aldosteronism. Upon calculation of the aldosterone-to-renin ratio, only animals with the Sspo SNV showed higher ARRs in comparison to their wild-type littermates, suggesting possibly a particular role of this gene in the described phenotype.
Furthermore, it can be speculated that downregulation of the initial enzymes of steroidogenesis, such as StAR, Cyp11a1 and Hsd3b6 as displayed on Fig. 4, was due to a negative feedback loop by parallel autonomous aldosterone secretion. Consistent with the unchanged Cyp11b1 expression, no differences in corticosterone values could be observed in the study. Additionally, we observe a discrepancy between the moderate adrenal Cyp11b2 RNA expression and the significantly higher aldosterone values, aldosterone-to-renin ratios and number of CYP11B2 positively stained adrenocortical cells in mutant animals. The interpretation of the only mild Cyp11b2 upregulation with the presence of SNVs on some of the investigated genes (Sspo and much less $D g u o k)$ or the complete absence of upregulation in other cases (Hoxaas2, Clstn3) appears thereby more challenging. However, it is possible that even moderate increased Cyp11b2 RNA expression could result in a pronounced difference in protein expression possibly due to increased stability of this enzyme. This explanation would require further analysis. Another interesting observation in mutant animals (all four Sspo, Dguok, Hoxaas2 and Clstn3) is that the increase in aldosterone synthase expression seems to be based on the presence of aldosterone synthase expression in the middle and inner adrenocortical area. This alteration of the functional zonation of the adrenal cortex also needs further elucidation.

Taken together, from the identified candidate genes Atm, Tipin and Mapk6 seem to not be responsible for the investigated phenotype of primary aldosteronism, whereas no safe conclusion can be reached in the case of Sspo, Dguok, Hoxaas2 and Clstn3 and their potential role in PA. Ideally, to distinguish among those four genes, further breeding should take place to genetically separate them in strains carrying only one candidate SNV. Practically, this was not yet achieved after seven generations of breeding after embryo transfer (F1-F7), probably as all four genes are located in near regions of the same chromosome and thereby inherited together. Thus, further efforts will be necessary to rule in or out the role of these four genes in the pathogenesis of primary aldosteronism.

\section{Supplementary data}

This is linked to the online version of the paper at http://dx.doi.org/10.1530/ JME-16-0200.

Declaration of interest

The authors declare that there is no conflict of interest that could be perceived as prejudicing the impartiality of the research reported.

Published by Bioscientifica Ltd. 


\section{Funding}

This work was supported by a grant from the Deutsche Hochdruckliga and in part by a grant from the Bayerische Gleichstellungsförderung to $A S$ and funds from the People Programme (Marie Curie Actions) of the European Union's Seventh Framework Programme (FP7/2007-2013) under REA grant agreement n॰ 608765 to L G P-R.

\section{Acknowledgments}

The authors are indebted to Brigitte Mauracher, Sebastian Kaidel, Andreas Mayer and Sandra Hoffmann for excellent technical assistance.

\section{References}

Beuschlein F, Boulkroun S, Osswald A, Wieland T, Nielsen HN, Lichtenauer UD, Penton D, Schack VR, Amar L, Fischer E, et al. 2013 Somatic mutations in ATP1A1 and ATP2B3 lead to aldosteroneproducing adenomas and secondary hypertension. Nature Genetics $\mathbf{4 5}$ 440-444, 444e441-442. (doi:10.1038/ng.2550)

Beuschlein F, Fassnacht M, Assie G, Calebiro D, Stratakis CA, Osswald A, Ronchi CL, Wieland T, Sbiera S, Faucz FR, et al. 2014 Constitutive activation of PKA catalytic subunit in adrenal Cushing's syndrome. New England Journal of Medicine 370 1019-1028. (doi:10.1056/ NEJMoa1310359)

Boulkroun S, Beuschlein F, Rossi GP, Golib-Dzib JF, Fischer E, Amar L, Mulatero P, Samson-Couterie B, Hahner S, Quinkler M, et al. 2012 Prevalence, clinical, and molecular correlates of KCNJ5 mutations in primary aldosteronism. Hypertension 59 592-598. (doi:10.1161/ HYPERTENSIONAHA.111.186478)

Choi M, Scholl UI, Yue P, Bjorklund P, Zhao B, Nelson-Williams C, Ji W, Cho Y, Patel A, Men CJ, et al. $2011 \mathrm{~K}+$ channel mutations in adrenal aldosterone-producing adenomas and hereditary hypertension. Science 331 768-772. (doi:10.1126/science.1198785)

Clark AT, Goldowitz D, Takahashi JS, Vitaterna MH, Siepka SM, Peters LL, Frankel WN, Carlson GA, Rossant J, Nadeau JH, et al. 2004 Implementing large-scale ENU mutagenesis screens in North America. Genetica 122 51-64. (doi:10.1007/s10709-004-1436-6)

Daniil G, Fernandes-Rosa FL, Chemin J, Blesneac I, Beltrand J, Polak M, Jeunemaitre X, Boulkroun S, Amar L, Strom TM, et al. 2016 CACNA1H mutations are associated with different forms of primary aldosteronism. EBioMedicine 13 225-236. (doi:10.1016/j.ebiom.2016.10.002)

Davies LA, Hu C, Guagliardo NA, Sen N, Chen X, Talley EM, Carey RM, Bayliss DA \& Barrett PQ 2008 TASK channel deletion in mice causes primary hyperaldosteronism. PNAS 105 2203-2208. (doi:10.1073/ pnas.0712000105)

Diener S, Bayer S, Sabrautzki S, Wieland T, Mentrup B, Przemeck GK, Rathkolb B, Graf E, Hans W, Fuchs H, et al. 2016 Exome sequencing identifies a nonsense mutation in Fam46a associated with bone abnormalities in a new mouse model for skeletal dysplasia. Mammalian Genome 27 111-121. (doi:10.1007/s00335-016-9619-x)

Doi M, Takahashi Y, Komatsu R, Yamazaki F, Yamada H, Haraguchi S, Emoto N, Okuno Y, Tsujimoto G, Kanematsu A, et al. 2010 Saltsensitive hypertension in circadian clock-deficient Cry-null mice involves dysregulated adrenal Hsd3b6. Nature Medicine 16 67-74. (doi:10.1038/nm.2061)

Fernandes-Rosa FL, Williams TA, Riester A, Steichen O, Beuschlein F, Boulkroun S, Strom TM, Monticone S, Amar L, Meatchi T, et al. 2014 Genetic spectrum and clinical correlates of somatic mutations in aldosterone-producing adenoma. Hypertension 64 354-361. (doi:10.1161/HYPERTENSIONAHA.114.03419)

Fuchs H, Gailus-Durner V, Adler T, Aguilar-Pimentel JA, Becker L, Calzada-Wack J, Da Silva-Buttkus P, Neff F, Gotz A, Hans W, et al.
2011 Mouse phenotyping. Methods 53 120-135. (doi:10.1016/j. ymeth.2010.08.006)

Geller DS, Zhang J, Wisgerhof MV, Shackleton C, Kashgarian M \& Lifton RP 2008 A novel form of human mendelian hypertension featuring nonglucocorticoid-remediable aldosteronism. Journal of Clinical Endocrinology and Metabolism 93 3117-3123. (doi:10.1210/ jc.2008-0594)

Gordon RD, Stowasser M, Tunny TJ, Klemm SA, Finn WL \& Krek AL 1991 Clinical and pathological diversity of primary aldosteronism, including a new familial variety. Clinical and Experimental Pharmacology and Physiology 18 283-286. (doi:10.1111/j.1440-1681.1991.tb01446.x)

Hagge-Greenberg A, Snow P \& O'Brien TP 2001 Establishing an ENU mutagenesis screen for the piebald region of mouse Chromosome 14. Mammalian Genome 12 938-941. (doi:10.1007/s00335-001-2087-x)

Hannemann A, Bidlingmaier M, Friedrich N, Manolopoulou J, Spyroglou A, Volzke H, Beuschlein F, Seissler J, Rettig R, Felix SB, et al. 2012 Screening for primary aldosteronism in hypertensive subjects: results from two German epidemiological studies. European Journal of Endocrinology 167 7-15. (doi:10.1530/EJE-11-1013)

Heitzmann D, Derand R, Jungbauer S, Bandulik S, Sterner C, Schweda F, El Wakil A, Lalli E, Guy N, Mengual R, et al. 2008 Invalidation of TASK1 potassium channels disrupts adrenal gland zonation and mineralocorticoid homeostasis. EMBO Journal 27 179-187. (doi:10.1038/sj.emboj.7601934)

Hintsch G, Zurlinden A, Meskenaite V, Steuble M, Fink-Widmer K, Kinter J \& Sonderegger P 2002 The calsyntenins - a family of postsynaptic membrane proteins with distinct neuronal expression patterns. Molecular and Cellular Neuroscience 21 393-409. (doi:10.1006/mcne.2002.1181)

Hrabe de Angelis MH, Flaswinkel H, Fuchs H, Rathkolb B, Soewarto D, Marschall S, Heffner S, Pargent W, Wuensch K, Jung M, et al. 2000 Genome-wide, large-scale production of mutant mice by ENU mutagenesis. Nature Genetics 25 444-447. (doi:10.1038/78146)

Justice MJ, Carpenter DA, Favor J, Neuhauser-Klaus A, Hrabe de Angelis M, Soewarto D, Moser A, Cordes S, Miller D, Chapman V, et al. 2000 Effects of ENU dosage on mouse strains. Mammalian Genome $\mathbf{1 1}$ 484-488. (doi:10.1007/s003350010094)

Lifton RP, Dluhy RG, Powers M, Rich GM, Cook S, Ulick S \& Lalouel JM 1992 A chimaeric 11 beta-hydroxylase/aldosterone synthase gene causes glucocorticoid-remediable aldosteronism and human hypertension. Nature 355 262-265. (doi:10.1038/355262a0)

Lu Z, Wang Y, Chen F, Tong H, Reddy MV, Luo L, Seshadrinathan S, Zhang L, Holthauzen LM, Craig AM, et al. 2014 Calsyntenin-3 molecular architecture and interaction with neurexin 1alpha. Journal of Biological Chemistry 289 34530-34542. (doi:10.1074/jbc.M114.606806)

Mancia G, Fagard R, Narkiewicz K, Redon J, Zanchetti A, Bohm M, Christiaens T, Cifkova R, De Backer G, Dominiczak A, et al. 2013 2013 ESH/ESC guidelines for the management of arterial hypertension: the Task Force for the management of arterial hypertension of the European Society of Hypertension (ESH) and of the European Society of Cardiology (ESC). Journal of Hypertension 31 1281-1357. (doi:10.1097/01.hjh.0000431740.32696.cc)

Manolopoulou J, Bielohuby M, Caton SJ, Gomez-Sanchez CE, RennerMueller I, Wolf E, Lichtenauer UD, Beuschlein F, Hoeflich A \& Bidlingmaier M 2008 A highly sensitive immunofluorometric assay for the measurement of aldosterone in small sample volumes: validation in mouse serum. Journal of Endocrinology 196 215-224. (doi:10.1677/JOE-07-0134)

Mulatero P, Stowasser M, Loh KC, Fardella CE, Gordon RD, Mosso L Gomez-Sanchez CE, Veglio F \& Young WF Jr 2004 Increased diagnosis of primary aldosteronism, including surgically correctable forms, in centers from five continents. Journal of Clinical Endocrinology and Metabolism 89 1045-1050. (doi:10.1210/jc.2003-031337) http://jme.endocrinology-journals.org

DOI: 10.1530/JME-16-0200
() 2017 Society for Endocrinology Printed in Great Britain
Published by Bioscientifica Ltd 
Mulatero P, Tauber P, Zennaro MC, Monticone S, Lang K, Beuschlein F, Fischer E, Tizzani D, Pallauf A, Viola A, et al. 2012 KCNJ5 mutations in European families with nonglucocorticoid remediable familial hyperaldosteronism. Hypertension 59 235-240. (doi:10.1161/ HYPERTENSIONAHA.111.183996)

Noveroske JK, Weber JS \& Justice MJ 2000 The mutagenic action of N-ethyl-N-nitrosourea in the mouse. Mammalian Genome 11 478-483. (doi:10.1007/s003350010093)

Rathkolb B, Hans W, Prehn C, Fuchs H, Gailus-Durner V, Aigner B, Adamski J, Wolf E \& Hrabe de Angelis M 2013 Clinical Chemistry and Other Laboratory Tests on Mouse Plasma or Serum. Current Protocols in Mouse Biology 3 69-100. (doi:10.1002/9780470942390.mo130043)

Rinchik EM 1991 Chemical mutagenesis and fine-structure functional analysis of the mouse genome. Trends in Genetics 7 15-21. (doi:10.1016/0168-9525(91)90016-J)

Rindler MJ, Xu CF, Gumper I, Cen C, Sonderegger P \& Neubert TA 2008 Calsyntenins are secretory granule proteins in anterior pituitary gland and pancreatic islet alpha cells. Journal of Histochemistry and Cytochemistry 56 381-388. (doi:10.1369/jhc.7A7351.2007)

Rossi GP, Bernini G, Caliumi C, Desideri G, Fabris B, Ferri C, Ganzaroli C, Giacchetti G, Letizia C, Maccario M, et al. 2006 A prospective study of the prevalence of primary aldosteronism in 1,125 hypertensive patients. Journal of the American College of Cardiology $\mathbf{4 8}$ 2293-2300. (doi:10.1016/j.jacc.2006.07.059)

Russell WL, Kelly EM, Hunsicker PR, Bangham JW, Maddux SC \& Phipps EL 1979 Specific-locus test shows ethylnitrosourea to be the most potent mutagen in the mouse. PNAS 76 5818-5819. (doi:10.1073/ pnas.76.11.5818
Scholl UI, Goh G, Stolting G, de Oliveira RC, Choi M, Overton JD, Fonseca AL, Korah R, Starker LF, Kunstman JW, et al. 2013 Somatic and germline CACNA1D calcium channel mutations in aldosteroneproducing adenomas and primary aldosteronism. Nature Genetics $\mathbf{4 5}$ 1050-1054. (doi:10.1038/ng.2695)

Scholl UI, Stolting G, Nelson-Williams C, Vichot AA, Choi M, Loring E, Prasad ML, Goh G, Carling T, Juhlin CC, et al. 2015 Recurrent gain of function mutation in calcium channel CACNA1H causes earlyonset hypertension with primary aldosteronism. eLife $\mathbf{4}$ e06315. (doi:10.7554/elife.06315)

So A, Duffy DL, Gordon RD, Jeske YW, Lin-Su K, New MI \& Stowasser M 2005 Familial hyperaldosteronism type II is linked to the chromosome 7 p22 region but also shows predicted heterogeneity. Journal of Hypertension 23 1477-1484. (doi:10.1097/01. hjh.0000174299.66369.26)

Spyroglou A, Wagner S, Gomez-Sanchez C, Rathkolb B, Wolf E, Manolopoulou J, Reincke M, Bidlingmaier M, Hrabe de Angelis M \& Beuschlein F 2011 Utilization of a mutagenesis screen to generate mouse models of hyperaldosteronism. Endocrinology 152 326-331. (doi:10.1210/en.2010-1081)

Spyroglou A, Bozoglu T, Rawal R, De Leonardis F, Sterner C, Boulkroun S, Benecke AG, Monti L, Zennaro MC, Petersen AK, et al. 2014 Diastrophic dysplasia sulfate transporter (SLC26A2) is expressed in the adrenal cortex and regulates aldosterone secretion. Hypertension 63 1102-1109. (doi:10.1161/HYPERTENSIONAHA.113.02504)

Sutherland DJ, Ruse JL \& Laidlaw JC 1966 Hypertension, increased aldosterone secretion and low plasma renin activity relieved by dexamethasone. Canadian Medical Association Journal 95 1109-1119.

Received in final form 5 December 2016

Accepted 13 December 2016

Accepted Preprint published online 13 December 2016 (c) 2017 Society for Endocrinology Printed in Great Britain 